\title{
Da lama ao caos: um estuário chamado Baía de Guanabara
}

\author{
From mud to chaos: \\ an estuary called Guanabara Bay
}

Maria Angélica Maciel Costa

\section{Resumo}

0 objetivo deste artigo é analisar os "fluxos da água" na metrópole fluminense, as relações desiguais de poder envolvidas na gestão bem como a consequência dessa situação em áreas periféricas. Para tanto, lançamos mão de revisão bibliográfica, entrevista com gestores, usuários de água e representantes da sociedade civil; além de uma análise do "Cadastro de Usuários de Água", disponibilizado pelo órgão gestor. Verifica-se que no contexto de mutações sociais e espaciais ligadas à industrialização e aos investimentos vultosos para uma (nova) despoluição da Baía de Guanabara, a garantia de acesso à água, bem como o tratamento dado aos usuários, continua a variar de forma expressiva na metrópole fluminense.

Palavras-chave: usos múltiplos da água; ecologia política da água; Baía de Guanabara; gestão metropolitana de águas; fluxos de água.

\begin{abstract}
This paper aims to analyze the "water flow" in the city of Rio de Janeiro, the unequal power relations involved in its management, and the consequence of this situation in peripheral areas. To this end, we carried out a literature review, interviews with managers, water users and civil society representatives, and analyzed the Water User Registration provided by the governing body. We verified that in the context of social and spatial mutations linked to industrialization and to huge investments for a (new) cleaning-up of Guanabara Bay, the guarantee of access to water, as well as the treatment given to users, continues to vary significantly in Rio de Janeiro.
\end{abstract}

Keywords: multiple uses of water; political ecology of water; Guanabara Bay; metropolitan water management; water flows. 


\section{Introdução}

Nas metrópoles ao redor do mundo, é comum a água passar por uma série de transformações até chegar ao usuário final. Trata-se de modificações não apenas em termos de características físico/químicas, mas também em termos de suas peculiaridades sociais e seus significados simbólicos e culturais. Nas cidades capitalistas, ou pelo menos nas cidades onde as relações de mercado são a forma dominante de troca, a circulação de água também é parte integrante da circulação de dinheiro e capital (Swyngedouw, 2004). Assim como acontece com outros bens e serviços urbanos, a circulação de água (ou os serviços que envolvem o saneamento ambiental) está diretamente imbricada com a economia política e os sistemas de poder, que dão estrutura e coerência ao tecido urbano (ibid.).

Neste artigo, o intuito é analisar os problemas relacionados à "questão da água" na Região Hidrográfica da Baía de Guanabara. ${ }^{1}$ Pretende-se refletir sobre os "fluxos da água" na metrópole fluminense e as relações de poder envolvidas nesse campo. A relevância deste tema se deve ao fato de o estuário Baía de Guanabara encontrar-se encravado no centro da segunda Região Metropolitana (RM) mais importante deste país, cujos corpos hídricos se encontram em situação de degradação ambiental extrema, onde existem fortes desigualdades de poder político e econômico entre os usuários de água e entre os municípios que fazem parte deste território. Essa centralidade espacial contribuiu sobremaneira para que ali fosse realizada uma sucessão de projetos políticos de desenvolvimento econômico, um exemplo notório de "território usado", ${ }^{2}$ tal qual apresentado por Santos e Silveira (2001).
Em que pese o fato da poluição e industrialização crescente da Baía serem assuntos de interesse da mídia e população fluminense, o surgimento de novos investimentos na metrópole - principalmente aqueles ligados à realização de provas Olímpicas e à expansão da indústria do petróleo e petroquímica na RMRJ - colocam o estuário ainda mais no centro das atenções desde o início da década de 2010. Toda essa conjuntura tem fortes reflexos nas demandas e usos e direcionamento dos fluxos das águas na metrópole.

Acompanhamos boa parte desses projetos, pois as análises aqui empreendidas foram iniciadas no ano de 2008, no âmbito do projeto "Valoração da Água e Instituições Sociais: Subsídios para a Gestão de Bacias Hidrográficas na Baixada Fluminense, RJ". ${ }^{3}$ Nos anos de 2009 a 2013, a autora deste artigo também se dedicou a essa temática em sua tese de doutorado, desenvolvida no Instituto de Pesquisa e Planejamento Urbano e Regional (Ippur-UFRJ), também sob orientação desses professores.

Foi a partir dessas experiências que pudemos entender melhor a dinâmica do campo de gestão de águas no RJ. Começamos a frequentar reuniões do Comitê de Bacia Hidrográfica da Baía de Guanabara (CBH Guanabara) e visitar localidades com histórico de enchentes e falta de água, localizadas na Baixada Fluminense e que receberiam investimentos do Programa de Aceleração do Crescimento (PAC) para saneamento básico. Além das conversas (não gravadas) com população residente em beira de curso d'água, fizemos entrevistas (gravadas) com ambientalistas, gestores públicos, participantes do CBH Guanabara e outros. Entre 2008 e 2009, realizamos um total de 39 entrevistas. 
A segunda etapa dos trabalhos de campo foi iniciada em 2011, com foco nas análises etnográficas institucionais do CBH Guanabara. Entre 2012 e início de 2013, outras seis entrevistas foram realizadas, dessa vez apenas com membros titulares do Comitê. Participamos de reuniões do CBH Guanabara, seus subcomitês e câmaras técnicas; fizemos visitas técnicas na Área de Proteção Ambiental (APA) Guapimirim e na Estação de Tratamento de Águas (ETA) Alegria; participamos de eventos ligados ao campo estadual de gestão de águas e, por fim, fizemos visitas ao órgão gestor ambiental estadual, o Instituto Estadual do Ambiente (INEA), para coletar dados e tirar dúvidas.

Outro documento importante analisado foi o Cadastro Nacional de Usuários de Águas $(\text { CNARH })^{4}$ da Região Hidrográfica da Baía de Guanabara, cedido pelo INEA, referente aos anos de 2008 e 2012. Desse modo, foi possível extrair dados interessantes relativos tanto à extração de água, quanto aos lançamentos realizados por setores distintos de usuários de recursos hídricos. Essas informações foram dispostas em tabelas (item "Usos e usuários de água na metrópole fluminense" deste trabalho) para melhor ilustrar os "fluxos de água" na metrópole, e foram analisadas com 0 apoio dos argumentos de autores ligados à Ecologia Política. ${ }^{5}$

Adotamos essa perspectiva de análise pois temos como interesse contribuir para o debate sobre o futuro da gestão de recursos hídricos em áreas metropolitanas - uma questão que, a nosso ver, tem sido abordada, prioritariamente, de forma técnica e operacional. Aqui cabe acrescentar que para Santos (2003, p. 118), "a vida não é um produto da Técnica, mas da Política, a ação que dá sentido à materialidade" . ${ }^{6}$ Encontramos em Santos (2003) outras observações pertinentes à questão em debate. Para ele, na contemporaneidade, a tecnologia se pôs a serviço de uma produção em escala planetária, na qual nem os limites dos Estados, nem os dos recursos, nem os dos direitos humanos são levados em conta. "Nada é levado em conta, exceto a busca desenfreada do lucro, onde quer que se encontrem os elementos capazes de permiti-lo" (Santos, 2003, p. 118).

Neste caso, refletir sobre o "ciclo hidrossocial" 7 da água no contexto de uma grande metrópole, como a do Rio de Janeiro (RJ), envolve um olhar atento sobre os processos de urbanização e políticas de desenvolvimento adotadas. Assim, é necessário compreendê-los como um processo político ecológico, cujo o elemento água serve como ponto de partida para uma discussão que abarca outras questões. Para loris (2010), a ecologia política dos recursos hídricos lida com as contradições socionaturais relacionadas ao uso e à conservação da água sob a esfera de influência direta ou indireta dos processos de circulação e acumulação de capital, assim como das alternativas para sua superação em contextos históricos e culturais específicos. Uma análise responsável dos problemas de gestão de recursos hídricos deve, então, identificar responsabilidades coletivas, mas profundamente diferenciadas, entre os grupos sociais que interagem em um dado território (loris, 2010, p. 81).

Além do mais, à medida que as cidades crescem, tornam-se mais complexos os fluxos das águas urbanas, sejam elas destinadas ao abastecimento da população, à diluição de efluentes, ao escoamento das águas pluviais, ao uso industrial, dentre outras situações. 
No caso específico da metrópole fluminense, observa-se que a dinâmica urbana na Região Metropolitana do Rio de Janeiro (RMRJ) sofre influência direta dos problemas relacionados tanto aos alagamentos recorrentes nos meses de verão quanto da escassez hídrica - já que são poucos os mananciais de água existentes para abastecer a metrópole, sendo o principal deles o Guandu, que depende fortemente das águas transpostas do rio Paraíba do Sul para operar (Costa, 2013).

Por fim, é visível que a Baía de Guanabara é mais do que uma região hidrográfica cortada por rios e pequenos córregos; e vai muito além de um simples estuário retratado em "cartões postais". Séculos atrás, o principal ecossistema ali existente era o mangue; já nas últimas décadas sua configuração é o resultado de diferentes formas de apropriação dos territórios, da consolidação e sobreposição de políticas públicas variadas (cada uma com sua própria "institucionalidade") que regulamentam os usos da água ali empreendidos. Sendo assim, será com um olhar sobre a história desse território, que iniciaremos nossas análises.

\section{Baía de Guanabara: aspectos históricos e projetos da atualidade}

As primeiras memórias do Rio de Janeiro, no século XVI, são impregnadas de observações sobre a bela, exótica e perigosa natureza da Baía de Guanabara e tribos indígenas, seus habitantes originais. A colonização das margens da Baía e de suas bacias hidrográficas, pelos europeus, seguiu uma marcha ininterrupta através de florestas, pântanos e morros. Essa foi uma grande vantagem para a ocupação inicial do Rio: a disponibilidade, na retaguarda, de planícies cultiváveis (zona de produção de alimentos e materiais de exportação) e de fácil acesso por hidrovias (Lessa, 2000).

Convém ressaltar que o início da colonização foi também o começo da incessante exploração dos recursos naturais da Baía de Guanabara, não somente das matas existentes nas ilhas, mas também de todo seu recôncavo e mangue. Além da extração de pau-brasil, as florestas próximas da costa transformaram-se em um reservatório de madeiras e lenha combustível para uma série de atividades: desde caieiras, para a produção de cal, passando por armações para a pesca de baleia, olarias, fazendas para produção de farinha de mandioca e engenhos de açúcar (Coelho, 2007).

No século XVII, foi marcante o impulso ao desenvolvimento econômico do estado e crescimento demográfico alcançado, principalmente em função do apogeu do ciclo da cana-de-açúcar. ${ }^{8}$ Característica relevante, e que trouxe sérias consequências para os corpos hídricos locais, ainda durante o período colonial, foi o fato de a cidade ter se desenvolvido "apertada" entre os morros, lagoas e o mar. Na busca de espaço para implantação da cidade, neste que demonstrava ser um ambiente hostil ao urbanismo, iniciava-se a luta do homem contra as áreas úmidas, tais como brejos, pântanos e lagoas, em um processo de aterramento que duraria mais de três séculos (Coelho, 2007). Toda a zona central do Rio de Janeiro, do cais do Porto ${ }^{9}$ até a atual Avenida Beira-Mar, e da Praça VX até a Praça Tiradentes, por exemplo, está assentada sobre uma área de alagadiço aterrado. Nesses termos, pode-se afirmar que a terra 
no Rio de Janeiro não foi apenas conquistada, mas também construída (Lessa, 2000).

Silva (2005) acrescenta que o advento da atividade mineradora direcionou a dinâmica econômica da Colônia do Nordeste para o Sudeste brasileiro, tornando imprescindível o planejamento logístico e a melhoria da infraestrutura existente, com vistas ao desenvolvimento e à fiscalização da produção. Esse cenário esclarece, em grande parte, as motivações que ensejaram a transferência da capital administrativa da Colônia de Salvador (BA) para a cidade do Rio de Janeiro, em 1763. Nessa época, o território fluminense já havia se consolidado como importante região portuária para abastecimento dos navios que faziam a defesa do litoral Sul da Colônia (Silva, 2005).

Contudo, mesmo com a ascendência que a capital fluminense galgava no fim do século XVIII, início do século XIX, ainda era notória a precariedade da cidade nos quesitos saneamento básico e abastecimento de água, no período colonial. 0 ambiente insalubre, somado à falta de condições de higiene em que vivia a população fluminense, produzia um meio propício à propagação de doenças e a problemas de saúde pública (Carvalho, 1996).

A vinda da corte portuguesa, em 1808, marcaria profundamente a paisagem e os hábitos da cidade, então convertida no centro de decisão do Império Português. Segundo Cano (2002, p. 50), a transferência da corte sinalizou para o Brasil a antecipação do "processo de independência: a liberalização dos portos e a liberdade de comércio e da indústria praticamente liquidavam o estatuto colonial".

Outros importantes foram a Proclamação da República (1889) e o novo ciclo de urbanização do Rio de Janeiro, implementado pelo período de gestão do prefeito Pereira Passos (1902-1906). ${ }^{10}$ Foi a partir daí que as desigualdades espaciais e sociais, tanto da capital quanto da Baía de Guanabara, se acentuaram e se sobrepuseram ainda mais (Carvalho, 1996).

Nesse contexto, Chiavari (1985) lembra que, se o saneamento foi um problema recorrente nas grandes cidades, em uma dada fase de seu desenvolvimento, no Rio de Janeiro, em especial, esse problema assumiu grandes proporções, pois, além de ser uma "praga" que ameaçava a sobrevivência e reprodução da mão-de-obra, gerava o cancelamento de chegada de navios nos portos, algo que deveria ser combatido por uma cidade que ambicionava um papel de protagonista no cenário do comércio internacional.

Um século depois, especificamente na década de 1950, ${ }^{11}$ ocorre o momento auge do processo de poluição e degradação da Baía, coincidindo com o processo de desenvolvimento urbano-industrial da RMRJ. Britto (2003) lembra que os aterros que acompanharam a abertura da Avenida Brasil, conjugados à expansão das indústrias poluidoras, principalmente químicas, farmacêuticas e de refinaria, e ainda o espetacular crescimento populacional e a expansão urbana, conduziram a uma alteração radical na qualidade das águas, flora, fauna e balneabilidade das praias, e ao declínio da pesca. Os efluentes industriais, cada vez em maior escala, passaram a contaminar as águas com óleo, metais pesados, substâncias tóxicas e carga orgânica. A expansão urbana e populacional, sem o acompanhamento de serviços adequados de esgotamento sanitário, passou a responder, por sua vez, pela poluição provocada pelo esgoto doméstico não tratado, o qual, gradualmente, foi tornando as 
praias do interior da Baía impróprias para o banho (Britto, 2003).

Na história do estuário da Baía de Guanabara, cabe pontuar que foi relevante no século XX, início da década de 1990, o Programa de Despoluição da Baía de Guanabara, financiado pelo Banco Mundial e pelo Japan Bank for International Cooperation (JIBIC). Britto (2003) lembra que esse foi apresentado como um dos maiores conjuntos de obras de saneamento no Estado do Rio de Janeiro, tendo por objetivos gerais recuperar os ecossistemas ainda presentes no entorno da Baía de Guanabara e resgatar, gradativamente, a qualidade das águas e dos rios que nela desaguam, através da construção de sistemas de saneamento adequados. Contudo, esse programa foi um grande fracasso, pois teve uma efetividade muito bai$\mathrm{xa}$, sobretudo se analisado sob o viés do volume de recursos investidos pelos agentes financiadores externos (Britto, 2003; Sanches, 2000; Vieira, 2009).

A seguir, iremos nos deter em aspectos relevantes deste início de década de 2010.

\section{A Baía de Guanabara Olímpica e a Baía da "Petrobrás"}

Neste início de século XXI, há dois grandes projetos se sobrepondo na Baía de Guanabara, o primeiro deles diz respeito ao "uso olímpico esportivo" de suas águas e, o segundo, refere-se ao "uso industrial". E é à analise desses, que este tópico se deterá.

No início dos anos 1990, com o agravamento da crise de endividamento do Estado brasileiro e o colapso do planejamento urbano estatal, as iniciativas de planejamento urbano subsequentes a esse contexto passaram por um período de descrédito e desvalorização (Pires, 2010). Em 1993, a Prefeitura da Cidade do Rio de Janeiro (PCRJ) resolveu, inspirada no modelo de planejamento urbano de Barcelona, firmar um acordo com a Associação Comercial do Rio de Janeiro (ACRJ) e Federação das Indústrias (Firjan), para promoverem juntas o Plano Estratégico da Cidade do Rio de Janeiro (PECRJ). Assim, esse documento foi elaborado apostando que essa estratégia contribuiria para reverter o quadro de agravamento da crise urbana e a perda de investimentos, ${ }^{12}$ recolocando a Cidade em termos globais, inserindo-a em termos competitivos, em condições de atrair investimentos públicos e privados (Pires, 2010).

Desse modo, estavam dadas as condições para que se estabelecessem com toda a força, na cidade do Rio de Janeiro, os pressupostos do modelo neoliberal de planejamento, a fim de que fosse reforçada a "vocação olímpica" da cidade e criados investimentos visando à atração de megaeventos. Para tanto, os consultores internacionais de planejamento estratégico de cidades indicam que sediar megaeventos é uma eficiente ação de marketing urbano internacional e atração de investimentos públicos. Sobre isso, o próprio prefeito carioca, Eduardo Paes, confirma:

Tudo o que a gente faz como se fosse coisa da Olimpíada, de olímpico não tem nada. Os dois maiores eventos esportivos do mundo servirão, assim, de pretexto para realizar intervenções urbanísticas num curto espaço de tempo, numa escala comparável somente à gestão de Pereira Passos, o prefeito do início do século passado, que alçou o Rio à condição de Cidade Maravilhosa. (A Lição..., 2013, p. 40) 
Nessa mesma reportagem, o RJ é apresentado como um exemplo a ser seguido pelas outras metrópoles do país, e enaltecido por ser a cidade, capital de estado, que mais recebe investimentos em todo mundo.

Assim, com relação ao primeiro projeto citado, despoluir a Baía de Guanabara - chamada de "Baía Olímpica" por representantes do poder público e usuários de água durante eventos e reuniões, esse é um dos objetivos que compõem o chamado legado ambiental dos Jogos Olímpicos. 0 que se observa, então, é que o alardeado modelo "bem-sucedido" de Planejamento Estratégico de Cidades tem relação direta com os aspectos ambientais, sociais, econômicos e políticos da capital. 0 "otimismo fluminense" se deve, fundamentalmente, ao fato de a cidade ter sido uma das cidades- sede da Copa do Mundo de Futebol em 2014, e de receber também os Jogos Olímpicos, no ano de 2016.

Diante da grande expectativa a respeito dos "legados" que deixarão na cidade, para além dos dias de realização dos megaeventos, bem como do montante de dinheiro investido na RMRJ nesses anos, fica mais fácil visualizar "os jogos de poder e o poder dos jogos" (Oliveira, 2012). Tamanha é a força política desse megaevento esportivo que, sob a alegação de tornar a Baía adequada para realização de esportes náuticos, o Estado conseguiu retomar antigos projetos de despoluição, inclusive alguns dos que foram duramente criticados, como o PDBG. Sobre isso, o secretário estadual do ambiente, Carlos Minc, afirmou no ano de 2013: "o PDBG estava tão queimado que o programa mudou de nome para Saneamento Ambiental dos Municípios do Entorno da Baía de Guanabara (PSAM)". (Em 20 anos..., 2012).
Sobre isto, temos as palavras do presidente da Cedae, Wagner Victer (Rio Vai..., 2013):

0 presidente da Cedae explicou que 0 antigo Programa de Despoluição da Baía de Guanabara (PDBG), iniciado ainda nos anos 80 e que consumiu bilhões de dólares em recursos, com resultados tímidos, já foi superado pelas ações atuais. "0 PDBG original tinha um conjunto de obras com um nível de tratamento não tão profundo como 0 atual. As estações tinham um nível de tratamento primário só de $40 \%$ da carga orgânica. Hoje temos estações com nível secundário, que processam até $98 \%$ da carga orgânica. Em 2016, nós vamos entregar à população, aos turistas e aos atletas uma Baía de Guanabara muito mais limpa. (Rio Vai..., 2013)

Em que pesem o fracasso e o desperdício de dinheiro público que o PDBG logrou, sob o discurso de uso "Olímpico" das águas da Baía, uma série de novos investimentos econômicos e políticos está sendo retomada para o território. Assim como no PDBG, novamente o Banco Interamericano de Desenvolvimento (BID) concede empréstimo ao Governo do Estado para despoluição da Baía, dessa vez são US\$452 milhões. 0 próprio diretor do BID, ao ser questionado sobre isso em entrevista à $B B C$ Brasil, admite que houve falhas em projetos financiados pela instituição, mas diz apenas que "nenhum projeto é perfeito, e que o banco também aprende com os fracassos".

Segundo o site institucional da Secretaria Estadual do Ambiente (SEA), faz parte dos compromissos olímpicos assumidos pelo Governo do Estado com o Comitê Olímpico Internacional (COI) para a realização das Olimpíadas do Rio a meta de se alcançar o saneamento de $80 \%$ 
da Baía de Guanabara até 2016. Sendo assim, é possível ver que a realização das Olimpíadas serviu de "pretexto" para uma série de projetos, já que agora o Rio de Janeiro é mais do que uma cidade qualquer, é sim o "Rio Olímpico", tal qual pretende apresentar o folder abaixo.

Assim, a Baía de Guanabara apresenta-se como a região-chave para a implementação da política pública estruturante da SEA denominada "Pacto pelo Saneamento" - que contempla o "Plano Guanabara Limpa" e o "Programa de Saneamento dos Municípios do Entorno da Baía de Guanabara" (PSAM). Em maio de 2013, os investimentos previstos no Guanabara Limpa somavam pelo menos $\mathrm{R} \$ 6$ bilhões, incluindo desde obras de saneamento até restauração florestal nos rios que compõem a bacia hidrográfica. Contudo, a partir de meados de 2014, diversas foram as notícias veiculadas na grande mídia acerca das dificuldades para alcançar a "meta olímpica" de despoluir a Baía de Guanabara.
Com relação ao outro importante uso da água na Baía de Guanabara, seu uso industrial, ressaltamos a forte presença de empreendimentos relacionados à indústria do petróleo e petroquímica, no entorno e espelho d'água, principalmente, e também à indústria naval, estaleiros e portos. Cabe lembrar que, nas últimas duas décadas, o litoral do estado do Rio de Janeiro se tornou a região petrolífera mais importante do país, e uma das mais importantes do mundo; mais precisamente uma faixa do oceano atlântico, defronte à costa do norte fluminense, entre a cidade de Cabo Frio e a foz do rio Paraíba do Sul (Sevá, 2013). Na RMRJ, especificamente, ficam a Refinaria de Duque de Caxias (Reduc), da Petrobrás, e a Refinaria de Manguinhos, de capital privado. Nas ilhas do interior da Baía de Guanabara, a Ilha Redonda, a Ilha d'Água e a Ilha do Governador, localizam-se terminais de carga-descarga de produtos petrolíferos e parques de tanques com grande capacidade de armazenamento, ligados

Figura 1 - Folder campanha "Água Limpa para o Rio Olímpico"

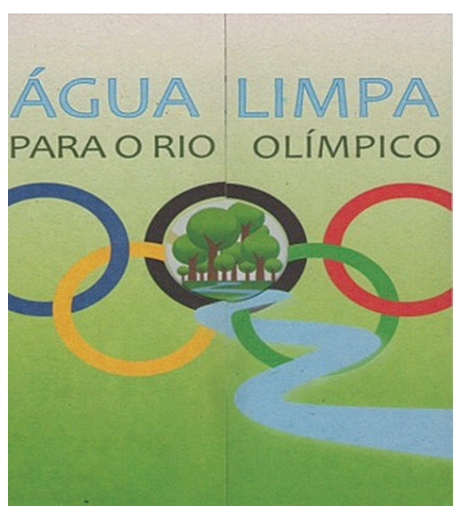

Fonte: Secretaria de Agricultura e Pecuária, RJ. 2013. 
à refinaria Reduc. Desses terminais, saem dutovias recentemente construídas sob o mar da Baía, para ligar com a refinaria Reduc e com o novo Complexo Petroquímico do Rio de Janeiro (Comperj) (ibid.). ${ }^{13}$

Sobre o Comperj, esse será o maior complexo industrial da América Latina, que ocupará uma área de 45 milhões de metros quadrados, localizada no município de Itaboraí, na RMRJ. Trata-se de um complexo de atividades petroquímicas voltadas, prioritariamente, à produção de resinas termoplásticas, a partir do refino do petróleo. ${ }^{14}$ Para escoar sua produção, está prevista a construção do "Arco Metropolitano do Rio de Janeiro", uma rodovia que ligará esse empreendimento ao porto de Itaguaí, contornando o fundo da Baía de Guanabara, ambos, Arco e Porto, impactando diretamente o planejamento urbano e regional da metrópole fluminense.

Com a entrada em operação do Comperj, a população do Leste da Baía de Guanabara deverá atingir um patamar da ordem de três milhões de habitantes, até o ano de 2030 (Coppetec, 2013), impactando diretamente a prestação de uma série de serviços urbanos. Para o suprimento da demanda futura de água, por exemplo, serão necessárias alternativas de abastecimento em caráter emergencial, visando complementar os mananciais atuais, principalmente porque sua principal fonte de abastecimento, o Sistema Imunama Laranjal, produz a vazão de $5.500 \mathrm{l} / \mathrm{s}$, enquanto a demanda atual é de $7.700 \mathrm{l} / \mathrm{s}$, ou seja, já trabalha com déficit (ibid.).

Analisando esses dois poderosos projetos - megaeventos e indústria do petróleo percebemos que um ponto de convergência entre eles é a força política de que estão instituídos. Nesse caso, é notório o esforço político e financeiro para despoluir a Baía de Guanabara e, assim, honrar o compromisso assumido com o Comitê Olímpico Internacional (COI), de um lado. E por outro, é perceptível um empenho similar para consolidar ainda mais essa região hidrográfica como um polo da indústria do petróleo. Em muitos momentos, esses dois projetos governamentais, em princípio contraditórios (despoluir versus "industrializar"), confluem politicamente. Um exemplo concreto são os recursos financeiros de medidas compensatória do Comperj, investidos na despoluição da Baía, e o Termo de Ajustamento de Conduta (TAC) da Reduc, assinado em 2011, que prevê investimentos na ordem de um biIhão de reais em ações que contribuirão para sanear a Baía de Guanabara, dentre outros.

Porém, se na atualidade o uso industrial é marcante, há algumas décadas era a pesca artesanal e industrial que marcava a paisagem e a economia da parte interna da Baía de Guanabara. Nos seus vários manguezais, que ainda não haviam sido aterrados, muitos moradores viviam de caçar caranguejos e siris e de extrair ostras e mexilhões (Sevá, 2013). Os grupos de pescadores artesanais que ainda resistem nessa atividade, na Baía de Guanabara, vivem em conflito permanente contra a apropriação privada e a poluição dos bens de uso comum que a indústria do petróleo e petroquímica gera nesse território (Pinto, 2013; Soares, 2012; Chaves, 2011).

Desse modo, convém reforçar que não são apenas os governantes e grandes empresários que têm interesses no território da Baía de Guanabara, existem outros grupos sociais que interagem nesse campo, interessados em perpetuar os usos habituais que ocorrem ali. Contudo, 
esses "outros" atores, muitas vezes, encontram-se em condições de desvantagem por não terem os capitais ${ }^{15}$ necessários para disputá-la em igualdade de condições. Para ilustrar essa informação, citaremos dois exemplos.

0 primeiro episódio selecionado será a audiência pública do Comperj, realizada no Ministério Público Estadual do RJ, no dia $6 / 8 / 2012$. Nesse evento, a sociedade civil organizada de Maricá, que luta para que o esgoto industrial do Comperj não seja lançado nos corpos hídricos desse município, recebeu como resposta do Inea que a empresa cumpre, de forma rigorosa, o que determina a norma da Resolução do Conselho Nacional de Meio Ambiente (Conama) n. 357, e que por isso o Estado autorizou o licenciamento ambiental da empresa. Em contrapartida, as lideranças sociais e os pescadores presentes contra-argumentaram dizendo que essa resolução do Conama não levava em consideração aspectos subjetivos, que somente quem vivencia e trabalha naquele território conhece - tais como o poder das marés em dispersar os contaminantes na região, bem como as rotas dos cardumes de peixe que serão atingidas. Alertaram ainda que, caso a obra do emissário para lançamento de esgotos fosse ali realizada, a poluição alcançaria inúmeras praias do lado leste da Baía de Guanabara, dentre outros impactos.

Sobre esse ponto, ficou notório que os discursos e argumentos dos profissionais que detêm o conhecimento técnico são baseados exclusivamente na lei em vigor, e que quando há o cumprimento das determinações técnicas legais, não cabe espaço para quaisquer outros tipos de questionamentos. Em contrapartida, os atores sociais que têm 0 conhecimento tradicional falam em nome dos saberes adquiridos na experiência diária com os recursos da natureza e insistem na relevância de seus argumentos, pois temem uma tragédia ambiental na região. Contudo, neste caso específico (emissário submarino para lançamento de efluentes industriais em Maricá), observamos que os pescadores podem "até reclamar", têm o direito de falar e expor sua opinião em eventos destinados ao debate público, mas não têm poder suficiente para alterar um projeto tão importante para o Estado quanto é o Comperj. Nessa audiência pública, vimos ainda o Estado defendendo os interesses das indústrias em detrimento dos anseios dos outros grupos sociais ali representados.

Outro exemplo são os pescadores artesanais da Baía de Guanabara, um grupo que sofre diretamente os efeitos da industrialização nesse território e que tem sido alvo de ameaças e atentados por contestar e tentar impedir os projetos que inviabilizam a pesca nessas águas. A essa categoria tem sido dado o papel de denunciar a apropriação privada desse território e lutar pela garantia das condições que permitam a reprodutibilidade de suas práticas sociais. 0 principal grupo organizado de resistência à supremacia da indústria de petróleo e petroquímica nas cercanias da Baía de Guanabara é a Associação de Homens e Mulheres do Mar (Ahomar). Apesar de esse grupo reclamar e participar de diversas reuniões e audiências públicas, o "constrangimento político" que eles criam não tem poder suficiente para modificar o projeto em curso na metrópole. Pelo contrário, muitos membros já sofreram atentados de morte, pescadores foram brutalmente assassinados e sua principal liderança necessita de escolta armada diariamente. 
No próximo item deste artigo, com base na análise dos dados do Cadastro de Usuários de Água, refletiremos sobre a intensificação dos usos de suas águas na RMRJ.

\section{Usos e usuários de água na metrópole fluminense}

Toda a efervescência de projetos e investimentos supracitados tem influência direta na direção que os fluxos da água na metrópole tomam. Ainda mais quando pensamos na situação atual de estresse hídrico vivido na RMRJ (Coppetec, 2013). Nesse contexto, cabe refletir sobre quais são as regiões beneficiadas, bem como quem são os atores que detêm o poder de decisão sobre o fluxo que a água toma na RMRJ.

Para iniciar uma reflexão sobre desigualdades ambientais relacionadas com a água na RMRJ, cabe um olhar mais atento sobre a Baixada Fluminense (lado oeste da RMRJ), um exemplo marcante de inserção da água em processos de controle político e circulação de capital, influenciados diretamente por relações desiguais de poder de decisão em termos de acesso e uso da água. Além do mais, no caso da água, as condições desiguais de apropriação não só acentuam as dificuldades de uso por uma parte da população, como também resultam em situações de maiores riscos associados ao uso do território para fins de moradia (Fracalanza et al., 2013).

Na Baixada Fluminense localizam-se cursos d'água intensamente poluídos, que desaguam na Baía de Guanabara (bacia hidrográfica dos rios Iguaçu, Botas e Sarapuí), fruto da presença de um parque industrial bastante complexo e da ausência de políticas efetivas de saneamento básico, ambos os fatos contribuindo de forma significativa para a poluição do estuário. Há ainda, nessa região, um problema histórico de "falta de água", em razão do abastecimento de água intermitente em muitos bairros e de "excesso de água", devido às recorrentes enchentes durante os meses chuvosos do verão.

Assim, neste tópico, os "fluxos da água" servirão como fio condutor para uma análise das situações tidas como de injustiça ambiental, vividas pelos moradores da região. Para tanto, realizaremos uma analogia entre as direções dos fluxos de pessoas e o fluxo de água que cruza o lado oeste da RMRJ.

Em um primeiro momento, destacamos a situação de dependência econômica da Baixada Fluminense em relação ao Rio de Janeiro e seu papel de fornecedora de mão de obra barata para a capital, uma vez que a fraca economia local obriga grande parte de seus moradores a realizar longos deslocamentos em busca de emprego e renda (Simões, 2006). Aqui cabe ressaltar que a cidade do Rio de Janeiro tem características especiais no contexto metropolitano devido à centralidade econômica e política que exerce diante dos demais municípios (Lago, 2009). Nesse caso, são os moradores da Baixada que sofrem o ônus de ter que se deslocar para trabalhar em locais distantes de sua residência, encontrando dificuldades diversas nesse deslocamento de casa para o trabalho devido, principalmente, à precariedade do sistema de transporte público intermunicipal e engarrafamentos no trânsito em quase toda a RMRJ (fatos esses rotineiramente divulgados na própria grande mídia). 
Por outro lado, quando observamos 0 deslocamento da água para abastecimento doméstico na região, o fluxo se inverte. Isso porque a população da Baixada está situada geograficamente nas proximidades do principal manancial de água da RMRJ, o Sistema Guandu, ${ }^{16}$ mas não se beneficia dessa situação, uma vez que inúmeros bairros da Baixada Fluminense sofrem escassez crônica dos serviços de abastecimento de água (Porto, 2001; Ioris e Costa, 2008). Enquanto isso, nos bairros da zona norte, centro e sul da cidade do RJ, área considerada mais "nobre", cujos bairros são chamados de "fim de linha" pela Cedae, por estarem distantes geograficamente das fontes de água bruta da Estação de Tratamento de Água Guandu (ETA Guandu), dificilmente falta água (Costa e loris, 2010). Desse modo, a proximidade geográfica do principal sistema de abastecimento não é garantia de que a água chegará de maneira regular e com qualidade confiável nas residências.

Esse exemplo nos mostra que é através das práticas de apropriação do mundo material, historicamente constituídas, que se configuram os processos de diferenciação social dos indivíduos, através da distribuição, acesso, posse e controle de território, fontes, fluxos e estoques de recursos materiais (Acselrad, 2004). Pode-se assim afirmar que os sujeitos, ou agentes sociais, são constituídos em função das relações que estabelecem no espaço social (Bourdieu, 1999).

As tabelas abaixo confirmam esta situação: grande parte da água que abastece a Região Hidrográfica V (RMRJ) é captada em municípios da Baixada, mas o município que mais realiza lançamentos é o RJ. Ou seja, a água, que é pesada e requer uma logística complicada para se deslocar, captada na Baixada, serve para fomentar o protagonismo econômico da capital no contexto nacional e internacional. Aqui, vale reforçar que a zona oeste do Rio de Janeiro não é "produtora" de água, uma vez que o Sistema Guandu, localizado no município de Nova Iguaçu, é beneficiado com uma transposição de água do rio Paraíba do Sul. De todo modo, mesmo que artificial, é a Baixada Fluminense que abriga o principal manancial de água da metrópole. A próxima figura mostra a carga total de lançamento de efluentes dos principais municípios usuários de água. 
Figura 2 - Os cinco municípios com maior vazão de captação de água (litros/hora)

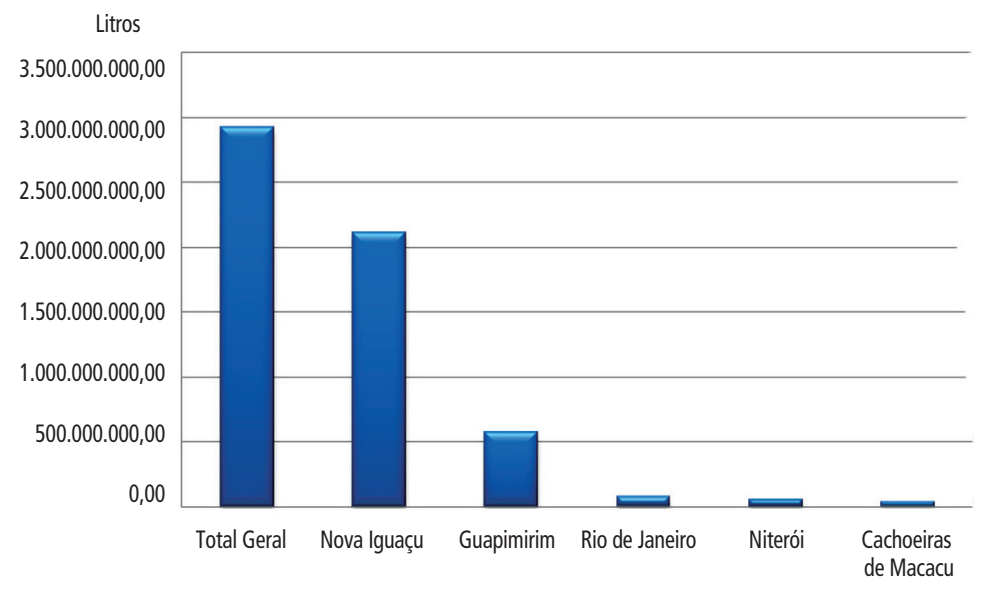

Fonte: Inea (2013); elaboração do autor.

Figura 3 - Os cinco municípios com maior vazão de lançamento de efluentes (litros/hora)

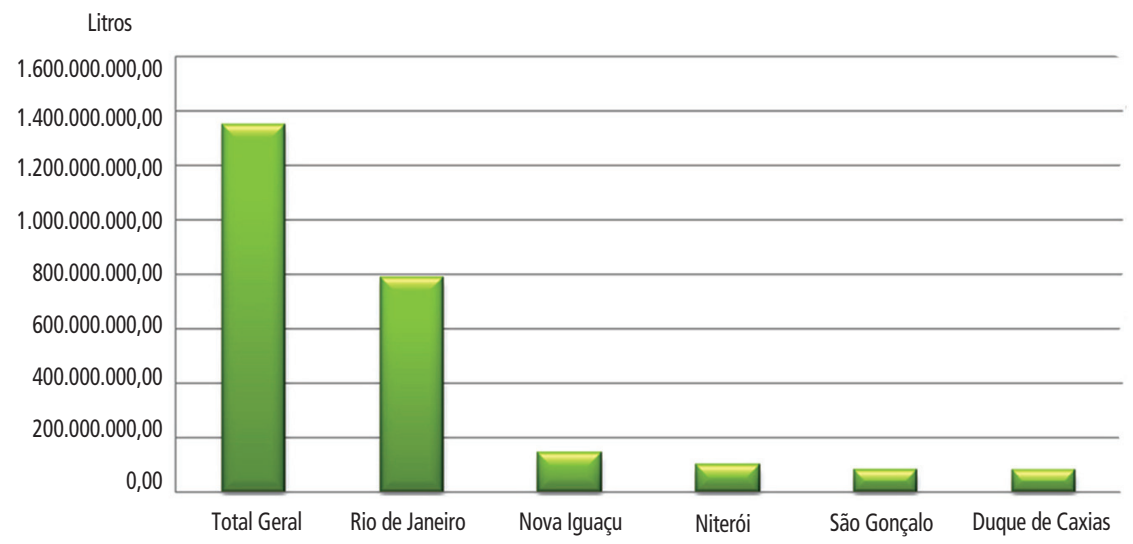

Fonte: Inea (2013); elaboração do autor. 
Observando as Figuras 2 e 3, conclui-se que a água proveniente dos municípios periféricos (Nova Iguaçu e Guapimirim, principalmente) é usada e descartada na capital, o Rio de Janeiro. Mesmo considerando que a capital tem mais habitantes, se comparada aos municípios periféricos, ainda assim é possível comprovar o argumento dos autores ligados à "Ecologia Política da Água", de que tanto a distribuição dos serviços que envolvem o saneamento básico, quanto as obras de infraestrutura em uma cidade podem sinalizar (e fomentar) diferenciação social e de classe. Tal pressuposto confirma a necessidade de observação do quadro social, pois, de acordo com a abordagem aqui adotada, o fluxo de água no contexto urbano expressa diretamente fluxos de poder entre grupos sociais e fluxos de recursos financeiros, através da ocupação desigual do espaço e da decisão a respeito de investimentos públicos (Swyngedouw, 2004).

Nesses termos, é preciso levar em conta que, quando se trata de analisar os problemas ambientais no meio urbano, é preciso ter em mente que as responsabilidades são parcialmente coletivas. Isso porque, certos agentes se encontram em posição privilegiada para interferir na dinâmica territorial, de forma mais atuante e com mais poderes do que outros. Por ser "base da produção da diferenciação social dos indivíduos, a desigual distribuição de poder sobre os recursos configura assim as diversas formas sociais de apropriação do mundo material" (Acselrad, 2004a, p. 15). De forma complementar, "o futuro das cidades dependerá, em grande parte, dos conceitos constituintes do projeto de futuro dos agentes relevantes na produção do espaço urbano" (Acselrad, 2009, p. 47).
E é justamente sobre os "agentes relevantes", ou seja, aqueles que detêm o poder de decidir para onde vai a água disponível, qual direção será tomada por seus fluxos na metrópole, o eixo condutor das discussões realizadas no próximo tópico.

\section{0 protagonismo da Cedae na RMRJ}

Vale reforçar que, em decorrência da "efervescência olímpica" e econômica da cidade, novas empresas surgem e o mercado de trabalho torna-se bastante aquecido, fato esse que potencializa a migração de profissionais de diversas áreas para a capital fluminense, principalmente, e demais municípios da RMRJ. Consequentemente, o mercado imobiliário também entra em franca expansão, com o lançamento de centenas de novos empreendimentos, majoritariamente localizados na região da Barra da Tijuca, área nobre que concentra grande parte dos equipamentos olímpicos. Tudo isto impacta diretamente a demanda e distribuição de água na RMRJ. Nesse momento, é relevante recordar que sob o ponto de vista da Ecologia Política da Água, o fluxo de água no contexto urbano expressa diretamente fluxos de poder entre grupos sociais, assim como fluxos de recursos financeiros (Swyngedouw, 2004).

Para confirmar o aumento da demanda por água, o gráfico abaixo apresenta o aumento do número de empreendimentos que compõem o Cadastro Nacional de Usuários de Recursos Hídricos (CNARH), ou seja, usuários que solicitaram a outorga de uso da água para fins de licenciamento ambiental, ou apenas regularizaram sua solicitação junto ao Inea. 
Figura 4 - Evolução do CNARH no estado do Rio de Janeiro

(número de usuários cadastrados por ano)

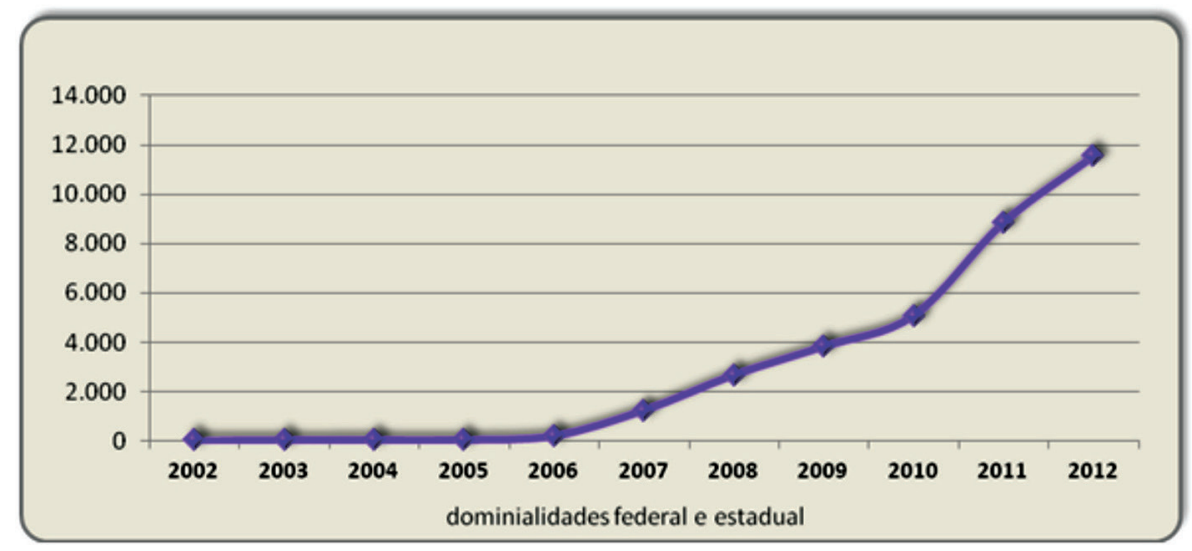

Fonte: Inea (2013).

Cabe aqui reforçar que a pressão sobre a rede fluvial (descarte de esgotos e efluentes industriais) e a demanda pela produção de água potável como insumo, provavelmente, irão gerar conflitos de uso, uma vez que, dificilmente, será possível atender a todos os demandantes. Isso porque, conforme nos lembra Castro (2010), a vazão do rio Guandu continua a mesma, e tais projetos, com investimentos públicos e privados, demandam enormes volumes de água. Historicamente, a transposição das águas do Paraíba do Sul para o Guandu significou a possibilidade de sobrevivência e expansão da cidade. No entanto, o quadro atual é incerto quanto à capacidade de suporte do atual sistema de abastecimento, em relação às possíveis demandas de água, e à diminuição da vulnerabilidade social quanto ao saneamento básico, vide a grave crise de abastecimento de água existente em São Paulo desde o final do ano de 2013.
Então, se o cenário não é favorável para garantir a demanda de água necessária para atender a toda a população e a todos os projetos em execução, com o agravante de que a metrópole paulista também sofre estresse hídrico, necessitando lançar mão das águas do Paraíba do Sul, cabe refletir sobre a segunda parte da questão proposta no início deste tópico. Assim, se não há água disponível para atender a todos os demandantes da metrópole fluminense, quem são os atores com o poder de decidir quais áreas geográficas serão contempladas ou quais serão os projetos contemplados? Para tentar responder a essa questão, utilizaremos novamente dados do cadastro de usuários de água, disponibilizado pelo Inea, para melhor visualizar quais são os principais setores usuários de água na RMRJ e como é a circulação dos fluxos da água na metrópole. 
Figura 5 - Vazão de captação $\left(\mathrm{m}^{3}\right)$ por tipo de uso da água na RHBG

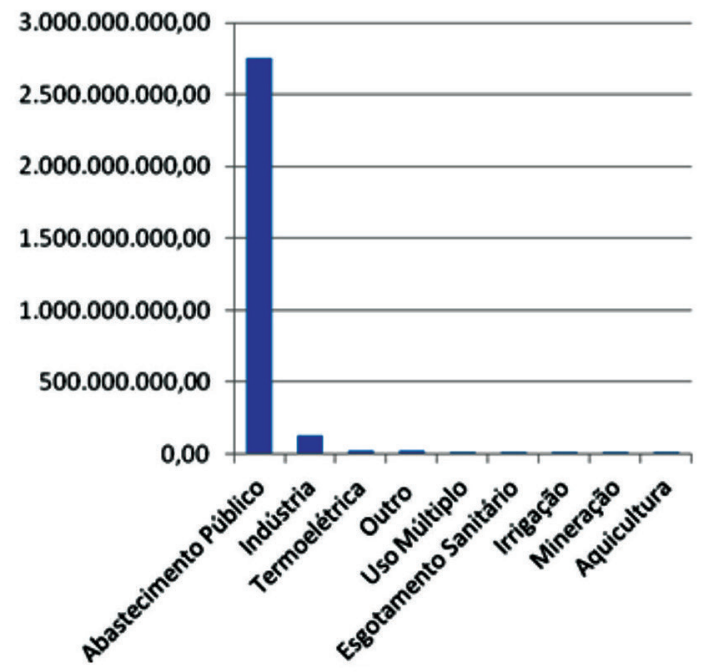

Fonte: Inea (2013); elaboração do autor.

À primeira vista, foi notória a superioridade do setor "saneamento básico", diante dos demais usuários, conforme Figura 5.

Ao verificar o nome das empresas cadastradas, percebemos que é a Cedae - prestadora de serviços de abastecimento público e esgotamento sanitário, quem domina fortemente as operações de captação e lançamento de águas na RHBG. Sediada na cidade do Rio de Janeiro, a Cedae é uma sociedade anônima de economia mista e capital aberto, sem ações listadas em Bolsa de Valores, cujo acionista majoritário é o Estado do Rio de Janeiro, responsável pela gestão da Companhia e detentor de $99 \%$ do capital votante e de $99 \%$ do capital total. 0 restante do capital é pulverizado entre 648 acionistas privados, em sua maioria pessoas físicas (Cedae, 2011). A Cedae garante o abastecimento de água a uma população de cerca de 13 milhões de pessoas, atende a 64 dos 92 municípios do Estado com abastecimento de água e obteve, em 2011, um faturamento médio mensal de $\mathrm{R} \$ 293$ milhões (Cedae, 2011).

Desse modo, podemos afirmar que é a Cedae quem define, em grande parte, os sentidos dos fluxos de água na metrópole. Ou seja, essa empresa, por sua atividade e grandeza, tem determinado, na prática, as maiores finalidades do uso da água. Segundo dados da própria Cedae (2011), a empresa afirma atender com abastecimento de água $86,3 \%$ da população (residentes nos municípios contratantes do serviço); e com relação ao esgotamento sanitário, declara que $52,1 \%$ dos 
usuários estão conectados à rede de esgoto. Ainda segundo dados fornecidos pela própria empresa, o índice de perdas de águas é da ordem de 31,2\% (Cedae, 2011). As perdas físicas de água na rede paulista, por exemplo, chegam a absurdos $45 \%$, em pelo menos metade da sua região metropolitana. Para Castro (2010), essas perdas são um crime ambiental; já Lutti (2014) declara que os administradores dessas empresas públicas de abastecimento - ou de economia mista, como é o caso da Sabesp - e outros agentes políticos deveriam ser pessoalmente responsabilizados por seus atos temerários, cujos resultados afetam a sociedade e 0 dinheiro público.

No caso da Cedae, foi possível verificar, em nossos trabalhos de campo, a insatisfação da população dos bairros da periferia da Baixada Fluminense, com relação a essa empresa. Cabe mencionar a falta de transparência e dificuldade de diálogo na relação entre Cedae e consumidores residenciais. Muitos moradores, mesmo pagando a conta de água, não recebem água nas suas casas. A Cedae só atende às reclamações (isto não significa que ela solucione os problemas) daqueles moradores que estão com suas contas de água em dia. Os inadimplentes não podem nem sequer fazer uma queixa relacionada a um cano estourado, à falta de água ou a qualquer outro problema (loris e Costa, 2009; Costa e loris, 2011). Muitos moradores mencionaram que por diversas vezes se organizaram em protestos e contrataram ônibus para levar as pessoas à sede da Cedae no Rio de Janeiro. Em uma ocasião, eles receberam como recomendação dos funcionários: "orar para chover, que é o melhor que vocês podem fazer..." (entrevista com os residentes em Duque de Caxias, 6/7/2008).
No caso específico das periferias da RMRJ, o resultado de tanto descompasso e descontinuidade nas políticas públicas de saneamento básico metropolitano é a cena, ainda muito comum, de moradores saindo de sua casa com uma sacolinha plástica de supermercado amarrada aos pés para proteger os sapatos, evitando assim chegar ao trabalho ou à escola com os pés sujos por lama. Em entrevista com o Secretário Municipal de Participação Social da Prefeitura de Nova Iguaçu, ${ }^{17}$ por exemplo, esse afirmou que na Baixada Fluminense 0 conceito de cidadania ainda está muito associado ao fato de o morador não ter lama na porta de sua casa.

\section{Considerações finais}

As análises realizadas apontam que os fluxos de águas que serpenteiam a Região Hidrográfica da Baía de Guanabara foram, e continuam sendo, apropriados como parte de uma estratégia que privilegia a produção capitalista do espaço. Tendo como base incentivos e políticas de Estado que fomentam a continuidade da grande exploração territorial direcionada à inserção brasileira na economia global. Contudo, críticas vêm sendo apontadas referentes aos poucos espaços políticos abertos para o debate sobre esses investimentos, apesar da existência de inúmeros arranjos políticos ditos participativos, criados nas décadas de 1990 e 2000.

0 projeto (dito) de desenvolvimento em curso na metrópole envolve fomentar a industrialização na Região Hidrográfica da Baía de Guanabara e inviabilizar outros tipos de usos e usuários de água, tais como os pescadores artesanais que se mostram presentes. 
No depoimento do pescador Alexandre Anderson, líder da Ahomar, realizado na OAB em agosto de 2012, esse reforçou o papel exercido pela atual "coalizão de poder", composta pelos governos federal, estadual, municipal e grandes empresários, no contexto da política desenvolvimentista em curso na RMRJ. Lembrou ainda que a industrialização do entorno da Baía de Guanabara sofreu grande impulso na última década e vem minando a possibilidade de realização de outros tipos de uso da água na Baía.

Os desafios desse sistema de gestão de águas implementados a partir da Política Nacional de Recursos Hídricos, baseado numa gestão que se pretende democrática e descentralizada, são de difícil solução no curto prazo e extrapolam a escala da metrópole, bem como a capacidade das instituições "hídricas" em resolvê-los, tais como os Comitês de Bacia Hidrográfica. Envolvem, antes de tudo, uma escala supranacional, cujo contexto tem se mostrado impregnado com os ideais das políticas econômicas neoliberais. É relevante salientar que mesmo uma política de águas bem-sucedida não é capaz de interferir naqueles setores colocados pela estrutura do Estado como fora da esfera decisória participativa. $\mathrm{Na}$ Baía de Guanabara, por exemplo, há múltiplas institucionalidades e diversas políticas públicas nela incidentes.

De forma geral, a busca por uma meIhor 'governança' (noção fundamental do aparato de regulação e gestão de recursos hídricos, como se pode verificar no texto da Lei 9433/1997) produziu uma significativa mudança de discurso nos últimos anos, mas sem que se identifiquem oportunidades concretas para democratizar o poder de decisão e vontade do Estado em compartilhá-lo, vide a falta de protagonismo do CBH Guanabara no campo de gestão de águas (Costa, 2013).

A insustentabilidade da água é, portanto, não apenas relacionada com o mau estado dos sistemas hídricos e a precariedade dos serviços públicos metropolitanos, mas está profundamente enraizada nos padrões de uso e conservação da água em um contexto de forte desigualdade de poder entre usuários de água - vide o protagonismo exercido pela Cedae - e os formuladores de políticas públicas.

Ademais, observa-se que o fundamento da Política Nacional de Recursos Hídricos (Brasil, 1997) que diz que, em um contexto de escassez, o uso prioritário da água deverá ser o abastecimento humano e a dessedentação de animais não é cumprida - já que dificilmente há falta de água para as indústrias. Já o cidadão comum, que necessita da água para sobrevivência diária, é nomeado pelas empresas de saneamento básico por "usuário" e deverá se encaixar em uma categoria preestabelecida - usuário residencial, comercial ou industrial, e pagar pelo seu uso, consequentemente. Observa-se assim que, com as reformas liberalizantes, a cidadania foi ressignificada e os direitos transformam-se em uma ficção retórica; em lugar de sujeitos de direitos surge a figura do usuário de serviços (Telles, 1999). Assim, a excessiva burocratização e racionalização formal do direito, do Estado, da administração pública, dentre outros, implica uma adaptação do modo de vida e de trabalho aos pressupostos econômicos e sociais gerais da economia capitalista, gerando assim um desprezo cada vez maior pela 
essência qualitativa das coisas e das pessoas (Lukács, 1974). Nesse contexto, o objetivo de despoluir a Baía de Guanabara não deveria ser tratado com uma "meta olímpica", e, sim, uma "meta cidadã".
Sem identificar a politização dos problemas relacionados aos "fluxos da água na metrópole", a discussão e a formulação de respostas ficam circunscritas a temas superficiais e que não conduzem a soluções efetivas.

\section{Maria Angélica Maciel Costa}

Universidade Federal Rural do Rio de Janeiro, Núcleo de Estudos e Pesquisas em Turismo, Laboratório Estado, Trabalho, Território e Natureza. Seropédica/RJ, Brasil.

mangelicamc@hotmail.com

\section{Notas}

(1) É importante aqui explicar que neste trabalho o recorte espacial selecionado não se limita apenas ao espelho d’água da Baía de Guanabara, e, sim, à sua Região Hidrográfica. O Instituto Estadual do Ambiente (Inea), órgão gestor responsável pela política ambiental em nível estadual do Rio de Janeiro (RJ), em 2006, dividiu o estado do RJ em 11 Regiões Hidrográficas. Nomeou de Região Hidrográfica da Baía de Guanabara (RHBG) a área que inclui, além da própria Baía (espelho d'água), 17 municípios (total ou parcialmente) e oito bacias hidrográficas. Observando os contornos dado à RHBG, uma primeira questão a ser levantada envolve a escala de gestão, ou seja, refere-se ao fato de que a RHBG corresponde à, praticamente, aos mesmos contornos geográficos da RMRJ.

(2) Para os autores, o "território usado" seria o próprio meio técnico-científico informacional que, em contextos metropolitanos, ganha dimensão e vitalidade devido aos múltiplos usos e, sobretudo, à disputa de usos.

(3) Com apoio parcial do CNPq, edital CT-Hidro, sob orientação dos professores Henri Acselrad e Antônio loris.

(4) O CNARH foi desenvolvido pela Agência Nacional de Águas (ANA), em parceria com autoridades estaduais gestoras de recursos hídricos. O objetivo principal é permitir conhecer o universo dos usuários das águas superficiais e subterrâneas em uma determinada área, bacia ou mesmo em âmbito nacional. O conteúdo do CNARH inclui informações sobre a vazão utilizada, local de captação, denominação e localização do curso d'água, empreendimento do usuário, sua atividade ou a intervenção que pretende realizar, como derivação, captação e lançamento de efluentes. O preenchimento do cadastro é obrigatório para pessoas físicas e jurídicas, de direito público e privado, que sejam usuárias de recursos hídricos, sujeitas ou não à outorga (ANA, 2003). 
(5) Ao não dissociar 'natureza e sociedade', e 'tempo e espaço', a Ecologia Política nos auxilia a visualizar melhor a clara manifestação dos interesses dos detentores de poder econômico em se apropriar cada vez mais dos bens naturais tidos, segundo certas concepções, como capital natural (Bordalo, 2008).

(6) Apesar da "vida não ser um produto da técnica", tal qual afirmou Milton Santos, são inúmeros os exemplos onde o conhecimento técnico subjuga os modos de vida de populações rurais ou tradicionais no Brasil. Zhouri et al. (2011), por exemplo, citou o caso das comunidades a jusante da represa de Irapé, em Minas Gerais, que tiveram o seu modo de vida alterado após o barramento das águas. Durante os embates de resistência ao empreendimento, opiniões diversas se confrontaram. De um lado, a população argumentava que a água piorou de qualidade após a construção da barragem, porque apresentava cheiro ruim, gosto ruim (tanto que "nem os animais bebiam", era o que diziam os entrevistados), e que o represamento da água alterou o ciclo natural das cheias e das vazantes, sendo esste primordial para viabilizar a agricultura familiar. Do outro lado, os técnicos responsáveis contra argumentavam dizendo que as mudanças foram apenas estéticas, pois a água continuava a mesma de sempre, Classe 2 , segundo parâmetros técnicos definidos pelo Conama, e, sendo assim, não havia motivos para reclamar.

Para Zhouri et al. (2011), a resposta estritamente técnica desconsiderou, desprezou o sofrimento diário das pessoas. Além do mais, a obra trouxe, sim, graves consequências sociais e econômicas, pois o represamento da água suprimiu as referências temporais e espaciais comunitárias, já que "a seca e a cheia" do rio organizavam o trabalho comunitário segundo as estações climáticas anuais. Por outro lado, da nova paisagem criada, onde a empresa abre as comportas à sua revelia, nada se sabe. Perdem-se, assim, conhecimentos situados, fatores sensoriais e corpóreos, podendo levar à extinção as experiências de manejos comunitários, ainda existentes naquela região (Zhouri et al., 2011).

(7) Swyngedouw (2004) elegeu a água como um fio condutor, a partir do qual seria possível revelar uma série de relações sociais que perpassam processos espaciais de diferentes ordens. $O$ simples movimento de uma gota de água que é engarrafada para ser vendida como mercadoria, por exemplo, pode demonstrar a complexidade do Ciclo Hidrossocial - uma vez que a interferência humana, os usos realizados e as relações sociais (de poder) são partes fundamentais desta trajetória.

(8) Na época, funcionavam aproximadamente 120 engenhos no entorno da Baía, os quais contribuíram para o processo de alteração dos ecossistemas da região, já que as matas litorâneas foram sistematicamente dizimadas para o plantio dos canaviais e abastecimento das fazendas (Coelho, 2007).

(9) É preciso citar também o importante papel exercido pela Baía de Guanabara de "porto colonial", local onde se praticavam as grandes transações comerciais, responsáveis pela expansão mercantil e agrária do Rio de Janeiro. Os portos passaram a possuir ter grande relevância, principalmente a partir do ciclo do ouro, com a descoberta dos minérios preciosos da região das Gerais, em 1695. Sendo assim, foi relevante o papel geopolítico desempenhado pela Baía de Guanabara: enquanto a navegação era a base do sistema de transporte, a Guanabara era o seu escoadouro natural, a planície que, após vencida a Serra do Mar, possibilitava a conexão com o ouro das Minas Gerais (Lessa, 2000). 
(10) Para melhorar a imagem da cidade no contexto internacional, o Plano de 1903, conhecido por "Reforma Passos", serviu de base à remodelação do Rio de Janeiro. Inspirada na Paris de Haussmann, a Reforma Passos surgiu, sobretudo, "como uma autêntica ação "civilizatória" sobre os trópicos, capaz de abrir ao país as vias da modernidade" (Carvalho, 1996, p. 167). No trecho abaixo, a autora ressalta o caráter secundário que a natureza, bem como a Baía de Guanabara, representou neste momento.

(11) Também em meados do século XX, não podemos deixar de citar que um fato político relevante foi a transferência do governo federal do Rio de Janeiro para Brasília, quando então o antigo Distrito Federal tornou-se estado da Guanabara. Anos mais tarde, em 1975, a fusão dos estados da Guanabara e do Rio de Janeiro criou o novo estado do Rio de Janeiro e um novo município capital, a cidade do Rio de Janeiro, que passou a conviver com a escassez de recursos para os encargos assumidos. Trata-se de uma situação muito diferente do que acontecia antes, pois, como Distrito Federal e depois estado da Guanabara, o Rio dispunha de uma quantidade razoável de recursos federais e estaduais. Além de perder funções administrativas em 1960, em 1975 a cidade perdeu os recursos de estado.

(12) Aqui convém lembrar que foi um "golpe duro" quando na década de 1950 a cidade do RJ deixa de ser a capital brasileira, que foi transferida para Brasília.

(13) Para Sevá (2013), a atividade petrolífera é marcante na paisagem da Baía de Guanabara, devido à presença dos vários estaleiros, navios e plataformas. Menos visíveis, mas igualmente relevantes para a indústria petrolífera, são os gasodutos e canalizações das empresas Comgás e GasRio, que distribuem gás natural para consumidores comerciais, coletividades e residências em muitos bairros do Rio, e para as mais importantes indústrias da RMRJ. Lembra ainda que, na capital carioca, estão sediados alguns órgãos que compõem o "cérebro" dessa indústria no país, tal como a Agência Nacional do Petróleo (ANP), além das sedes da Petrobras e da sua subsidiária de transportes, a Transpetro, e a sua subsidiária de comercialização, a BR Distribuidora.

(14) Convém aqui lembrar que, dentre todas as atividades envolvidas na cadeia produtiva do petróleo brasileiro, a etapa do refino do óleo é uma das que possuem têm tecnologia mais defasada. Esste fato assumiu dimensão catastrófica no ambiente e junto à opinião pública quando do acidente da Refinaria de Duque de Caxias, em 2000, o mais grave já ocorrido na baía de Guanabara, em decorrência do desgaste de oleodutos com manutenção precária (Sevá, 2013).

(15) Bourdieu (1997) afirma que a capacidade de dominar o espaço, principalmente apropriando-se (material ou simbolicamente) de bens raros (públicos ou privados) que se encontram desigualmente distribuídos, depende do capital acumulado (econômico, cultural, social, e outros) que cada ator tem.

(16) A Estação de Tratamentos de Águas do Guandu, localizada no município de Nova Iguaçu (lado oeste da RMRJ), é uma transposição de águas do Paraíba do Sul e abastece grande parte da metrópole.

(17) Entrevista realizada no ano de 2008. 


\section{Referências}

ACSELRAD, H. (2004a). "As práticas espaciais e o campo dos conflitos ambientais". In: ACSELRAD, H. (org.) Conflitos ambientais no Brasil. Rio de Janeiro, Relume Dumará.

(2004b). "Justiça ambiental: ação coletiva e estratégias argumentativas". In: ACSELRAD, H.; HERCULANO, S. e PÁDUA, J. A. (orgs.). Justiça ambiental e cidadania. Rio de Janeiro, Relume Dumará.

(2009). "Sentidos da Sustentabilidade Urbana". In: ACSELRAD, H. (org.). A duração das cidades. Sustentabilidade e risco nas políticas urbanas. Rio de Janeiro, Lamparina.

AGÊNCIA BRASIL (2013). Rio vai investir R\$ 2 bilhões para despoluir praias, lagoas e a Baía de Guanabara até as Olimpíadas. Brasília, 4 de junho. Disponível em: http://agenciabrasil.ebc. com.br/noticia/2013-06-04/rio-vai-investir-r-2-bilhoes-para-despoluir-praias-lagoas-e-baia-deguanabara-ate-olimpiadas. Acesso em: 5 jun 2013.

A LIÇÃO que vem do Rio. Revista Época. Editora Globo. Edição especial. Rio de Janeiro, 9/3/2013. Disponível em: http://revistaepoca.globo.com/Brasil/Especial/noticia/2013/03/licao-que-vemdo-rio.html. Acesso em: 30 jun 2013.

AMADOR, E. S. (1992). "Baía de Guanabara: um balanço histórico". In: ABREU, M. de A. (org.). Natureza e sociedade do Rio de Janeiro. Rio de Janeiro, SMCTE/Divisão.

ANA (2003). Resolução n. 317, de 26 de agosto, que instituiu o Cadastro Nacional de Usuários de Águas (CNARH).

(2007). GEO Brasil: recursos hídricos: resumo executivo. Ministério do Meio Ambiente; Agência Nacional de Águas; Programa das Nações Unidas para o Meio Ambiente. Brasília, MMA; ANA.

BORDALO, C. A. L. (2008). A gestão dos recursos hídricos a luz da ecologia política: um debate sobre o controle público versus o controle privado da água no Brasil. Cuadernos de Geografía: Revista Colombiana de Geografía, n. 17.

BOURDIEU, P. (1997). “Compreender”. In: BOURDIEU, P. A miséria do mundo. Petrópolis/RJ, Vozes.

BRASIL (1997). Lei 9.433. Política Nacional de Recursos Hídricos. Brasília, Secretaria de Recursos Hídricos, Ministério do Meio Ambiente dos Recursos Hídricos e da Amazônia Legal.

BRITTO, A. L. (2003). Implantação de infra-estrutura de saneamento na região metropolitana do Rio de Janeiro: uma avaliação das ações do Programa de Despoluição da Baía de Guanabara. Revista Brasileira de Estudos Urbanos e Regionais, v. 5, n. 1.

CANO, W. (2002). Ensaios sobre a formação econômica regional do Brasil. Campinas, Ed. Unicamp.

CARVALHO, A. M. F. M. (1996). A Baía de Guanabara: os itinerários da memória. Revista USP. São Paulo, n. 30, pp. 156-169.

CARVALHO, C. M. D. de (1990). História da Cidade do Rio de Janeiro. Rio de Janeiro, Secretaria Municipal de Cultura/Departamento Geral de Documentação e Informação Cultural. Biblioteca Carioca.

CASTRO, C. (2010). Águas do Rio de Janeiro: da metrópole com riscos à metrópole dos riscos. Tese de Doutorado. Rio de Janeiro, Universidade Federal do Rio de Janeiro.

CASTRO, C. M. e FERREIRINHA, M. M. (2013). A problemática ambiental na Bacia Hidrográfica do Rio Guandu: desafios para a gestão dos recursos hídricos. Anuário do Instituto de Geociências - UFRJ. 
CASTRO, J. E. (2007). Water governance in the twentieth-first century. Ambiente \& Sociedade, v. X, pp. 97-118.

CEDAE - Companhia Estadual de Águas e Esgotos (2011). Relatório da Administração do Exercício de 2011. Rio de Janeiro. Disponível em: http://www.cedae.com.br/ri/Relat\%C3\%B3rio_da_ Administra\%C3\%A7\%C3\%A3o_2011.pdf. Acesso em: 5 jan 2013.

CHAVES, C. M. S. R. S. (2011). Mapeamento participativo da pesca artesanal da Baía de Guanabara. Dissertação de Mestrado. Rio de Janeiro, Universidade Federal do Rio de Janeiro.

CHIAVARI, M. P. (1985). "As transformações urbanas do século XIX”. In: DEL BRENNA, G. R. (org.). O Rio de Janeiro de Pereira Passos. Rio de Janeiro, Index.

CNI (2012). Avanços da indústria brasileira rumo ao desenvolvimento sustentável: síntese dos fascículos setoriais. Brasília, CNI.

CNRH (2000). Resolução n. 5, de 10 de abril. Diretrizes para a formação e funcionamento dos Comitês de Bacias Hidrográficas.

COELHO, V. M. B. (2007). Baía de Guanabara: uma história de agressão ambiental. Rio de Janeiro, Casa da Palavra.

COOPETEC (2013). Plano Estadual de Recursos Hídricos do Estado do Rio de Janeiro. R4 - Relatório Gestão de Recursos Hídricos. Coppe/UFRJ, Laboratório de Hidrologia.

CORRÊA, R. L. (1986). Região e organização espacial. São Paulo, Ática.

COSTA, M. A. M. (2013). Os fluxos de água na metrópole: usos múltiplos e gestão participativa na Baía de Guanabara. Tese de doutorado. Rio de Janeiro, Universidade Federal do Rio de Janeiro.

COSTA, M. A. M. e IORIS, A. A. R. (2010). Até a Última Gota: Complexidade Hidro Social e Ecologia Política da Água na Baixada Fluminense. Rio de Janeiro, Brasil. Anais Conferência Waterlat. São Paulo.

(2011). A distância entre teoria e prática: barreiras para um regime de gestão de águas participativo na Baixada Fluminense - RJ. In: XIV ENCONTRO NACIONAL DA ANPUR. Anais. Rio de Janeiro.

ECOlOgUS (2005). Plano Diretor de Recursos Hídricos da Região Hidrográfica da Baía de Guanabara. Rio de Janeiro.

FRACALANZA, A. P.; JACOB, A. M. e ECA, R. F. (2013). Environmental justice and water resources governance practices: re-introducing issues of equality to the agenda. Ambient. soc. [on line]

INEA (2012). Cadastro dos Usuários de Água da RMRJ do ano de 2012. Dados fornecidos em 2013.

IORIS, A. A. R. R. (2010). “Da Foz às Nascentes”. In: ALMEIDA, A. W. B. et al. (orgs.). Capitalismo globalizado e recursos territoriais: fronteiras da acumulação no Brasil contemporâneo. Rio de Janeiro, Lamparina.

IORIS, A. A. R. e COSTA, M. A. M. (2008). Valoração da água e instituições sociais: subsídios para a gestão de águas na Baixada Fluminense. Anais Semana IPPUR.

(2009). The challenge to revert unsustainable trends: uneven development and water degradation in the Rio de Janeiro Metropolitan Area. Sustainability, v. 1, n. 2, pp. 133-160. 
JORNAL ESTADÃO (2012). Em 20 anos despoluição da Baía de Guanabara vira esgoto. São Paulo, 21 fev. Disponível em: http://www.estadao.com.br/noticias/impresso,em-20-anos-despoluicao-dabaia-de-guanabara-vira-esgoto,851258,0.htm. Acesso em: 30 jun 2013.

LAGO, L. C. (org.) (2009). Como anda o Rio de Janeiro? Rio de Janeiro, Letra Capital/Coleção Observatório das Metrópoles.

LEME, M. C. S.; FERNANDES, A. e GOMES, M. A. F. (orgs.) (1999). Urbanismo no Brasil 1895-1965. São Paulo, Studio Nobel/FAUUSP/Fupam.

LESSA, C. (2000). O Rio de todos os Brasis: uma reflexão em busca de auto-estima. Rio de Janeiro, Record.

LITTLE, P. E. (2006). Ecologia política como etnografia: um guia teórico e metodológico. Horizontes Antropológicos. Porto Alegre, ano 12, n. 25, pp. 85-103.

LUKÁCS, G. (1974). História e consciência de classe: estudos de dialética marxista. Rio de Janeiro, Porto, Portugal, Elfos Ed./Publicações Escorpião.

LUTTI, J. E. I. (2014). Crise de abastecimento era uma tragédia anunciada. Revista Le Monde Diplomatique. Edição especial gestão de águas.

MMA (2006). Plano Nacional de Recursos Hídricos. Síntese Executiva - português. Ministério do Meio Ambiente, Secretaria de Recursos Hídricos.

OLIVEIRA, N. G. (2012). O poder dos jogos e os jogos de poder: os interesses em campo na produção de uma cidade para o espetáculo esportivo. Tese de Doutorado. Rio de Janeiro, Universidade Federal do Rio de Janeiro.

PINTO, R. G. (2013). “Pesca artesanal e conflito ambiental na Baía de Guanabara”. In: 50 anos da Refinaria Duque de Caxias e a expansão da indústria petrolífera no Brasil. Organização: Fórum dos atingidos pela indústria do petróleo e petroquímica nas cercanias da Baía de Guanabara conflitos socioambientais no Rio de Janeiro e desafios para o país na era do Pré-sal. Fundação Heinrich Boll, Rio de Janeiro.

PIRES, H. F. (2010). Planejamento e intervenções urbanísticas no Rio de Janeiro: a utopia do plano estratégico e sua inspiração catalã. Biblio 3W. Revista Bibliográfica de Geografía y Ciencias Sociales. Universidad de Barcelona, v. XV, n. 895 (13). Disponível em: http://www.ub.es/geocrit/ b3w-895/b3w-895-13.htm. Acesso em: 8 mar 2013.

RESENDE, V. F. (2002). "Planos e regulação urbanística: a dimensão narrativa das intervenções na cidade do Rio de Janeiro". In: OLIVEIRA, L. L. (org.). Cidade: história e desafios. Rio de Janeiro, Ed. Fundação Getúlio Vargas.

RIO DE JANEIRO (1999). Lei n. 3239, de 2 de agosto. Institui a política estadual de Recursos Hídricos; cria o Sistema Estadual de Gerenciamento de Recursos Hídricos.

RIO VAI investir R\$2 bilhões para despoluir praias, lagoas e a Baía de Guanabara até as Olimpíadas. Agência Brasil. Brasília, 4/6/2013. Disponível em: http://agenciabrasil.ebc.com. br/noticia/2013-06-04/rio-vai-investir-r-2-bilhoes-para-despoluir-praias-lagoas-e-baia-deguanabara-ate-olimpiadas. Acesso em: 5 jun 2013.

SANCHES, M. (2000). Elites globais e cidadãos locais: quem ganha com a despoluição da Baía de Guanabara? In: CONGRESSO LASA. Anais. 
SANTOS, M. (1994). Técnica, espaço, tempo: globalização e meio técnico-científico-informacional. São Paulo, Hucitec.

(2003). A natureza do espaço: espaço e tempo: razão e emoção. São Paulo, Hucitec

SANTOS, M. e SILVEIRA, M. L. (2001). O Brasil: território e sociedade no início do século XXI. Rio de Janeiro, Record.

SECRETARIA DO AMBIENTE e Petrobrás fazem campanha sobre sustentabilidade ambiental. Site INEA. Rio de Janeiro, RJ. Publicado em 09/07/2013. Disponível em: http://www.inea.rj.gov.br/noticias/ noticia_dinamica1.asp?id_noticia=2295. Acesso em: 19 jul 2013.

SEVÁ, O. (2013). "Riscos e prejuízos sociais e ambientais da indústria petrolífera. Uma introdução sobre o panorama do Brasil até 201". In: 50 anos da Refinaria Duque de Caxias e a expansão da indústria petrolífera no Brasil. Organização: Fórum dos atingidos pela indústria do petróleo e petroquímica nas cercanias da Baía de Guanabara conflitos socioambientais no Rio de Janeiro e desafios para o país na era do Pré-sal. Rio de Janeiro, Fundação Heinrich Böll.

SILVA, J. R. (2002). Os Esgotos do Rio de Janeiro - História do Sistema de Esgotos Sanitários da Cidade do Rio de Janeiro. Rio de Janeiro, Corbã.

SILVA, M. O. (2005). Rio nacional, Rio local: mitos e visões da crise carioca e fluminense. Rio de Janeiro, Senac.

SILVA, R. D. (2007). Território e desenvolvimento: as raízes da centralidade do Rio de Janeiro na economia nacional. Estudos Históricos, Rio de Janeiro, n. 40.

SILVA, R. T. (2004). "A regulação e o controle público da infraestrutura e dos serviços urbanos no Brasil”. In: DEÁK, C. e SCHIFFER, S. R. (orgs.). O processo de urbanização no Brasil. São Paulo, Edusp.

SIMÕES, M. R. (2006). A cidade estilhaçada: reestruturação econômica e emancipações municipais na Baixada Fluminense. Tese de Doutorado. Niterói, Universidade Federal Fluminense.

SWYNGEDOUW, E. (2004). Social power and the urbanization of water: flows of power. Oxford Geographical and Environmental Studies. Oxford.

TELLES, V. da S. (1999). Direitos sociais: afinal do que se trata? Belo Horizonte, UFMG.

VIEIRA, M. V. (2009). O Programa de Despoluição da Baía de Guanabara. Entraves Institucionais e Impactos Territoriais na Região Metropolitana do Rio de Janeiro. Dissertação de Mestrado. Rio de Janeiro, Universidade Federal do Rio de Janeiro.

ZHOURI, A. et al. (2011). A supressão da vazante e o início do vazio: água e "insegurança administrada" no Vale do Jequitinhonha - MG. Anuário Antropológico, pp. 23-53

Texto recebido em 25/jul/2014

Texto aprovado em 6/dez/2014 
